DOI: 10.17707/AgricultForest.61.3.12

\author{
Leila AMJAD, Houshang NOSRATI, \\ Fariborz ZAARE, Gholamreza DEHGHAN, \\ Mohamadali HUSAINPOURFAZI, Sayd-yahya SALEHI ${ }^{1}$
}

\title{
A NOVEL BETAINE ALDEHYDE DEHYDROGENASE GENE FROM Medicago sativa AND ITS EXPRESSION UNDER SALINITY
}

\begin{abstract}
SUMMARY
Betaine aldehyde dehydrogenase (BADH) has been reported from several plant species mostly halophytes as the most important enzyme responsible for salinity tolerance. We investigated the expression of $\mathrm{BADH}$ gene along with ionic and enzymatic accumulations in an alfalfa cultivar, Medicago sativa cv. Gara-Yonjeh, widely cultivated in saline soils across East-Azerbaijan Province, Iran. Five different $\mathrm{NaCl}$ concentrations of $0,50,100,150$ and $200 \mathrm{mM}$ were examined using 30 seeds for each treatment. The $\mathrm{Na}^{+}, \mathrm{K}^{+}, \mathrm{Ca}^{2+}$ and proline concentration were measured in cotyledon and young roots of seven-day-old seedlings under salinity stresses and controls. Total RNA was extracted and the mRNA levels of P5CS2 ( $\Delta^{1}$-pyrroline-5-carboxylate synthetase) and BADH (hereafter MsP5CS2 and MsBD1, respectively) were determined using semiquantitative RT-PCR analysis. MsBD1mRNA was reverse-transcribed and then was amplified using PCR. The amplified MsBD1 DNAs were cloned. Our results showed that $150 \mathrm{mM} \mathrm{NaCl}$ was the stress threshold concentration for the young seedlings. The accumulation of the cations and proline significantly increased by increasing $\mathrm{NaCl}$ concentration from 0 to $150 \mathrm{mM}$. The mRNA levels of MsP5CS2 and MsBD1 increased in both cotyledons and roots at $150 \mathrm{mM}$ compared to control. A 1518 basepair cDNA fragment coding for MsBD1, and its proposed 505-amino acid sequences were characterized in Medicago sativa cv. GaraYonjeh. These DNA and amino acid sequences showed high homology with $\mathrm{BADH}$ gene/amino acid sequences previously reported from several other plant species. Our study shows that genic and ionic mechanisms are simultaneously employed in this cultivar to cope with salinity.

Keywords: Betaine aldehyde dehydrogenase, gene expression, Medicago sativa, pyrroline-5-carboxylate synthetase, molecular cloning, salinity tolerance.

\section{INTRODUCTION}

Salinity is one of the most important abiotic factors limiting plant growth and productivity. Under salt stress, plants have evolved complex mechanisms for

\footnotetext{
${ }^{1}$ Leila Amjad, Houshang Nosrati (Corresponding author: hnosrati@tabrizu.ac.ir), Mohamadali Husainpourfazi, Sayd-yahya Salehi, Department of Plant Science, University of Tabriz IRAN, Fariborz Zaare, Department of Agricultural Science, University of Tabriz IRAN, Gholamreza Dehghan, Department of Animal Science, University of Tabriz, IRAN

Note: The authors declare that they have no conflicts of interest. Authorship Form signed online.
} 
adaptation to osmotic ionic stresses caused by high salinity. The most widely distributed strategy of response to hyperosmotic stress is the accumulation of compatible solutes, which protect the cells and allows growth (Silva-Ortega et al. 2008). Osmoregulation is a fundamental phenomenon developed by bacteria, fungi, plants, and animals to overcome osmotic stress (Boscari et al. 2002).

Proline is one of the most effective compatible solutes, which plants widely use to cope with the most of environmental stresses including salinity and droughtness. The osmolyte role of proline under environmental stresses e.g. salinity and droughtness has been reported in many plant families including Fabaceae, Tamaricaceae, Poaceae and Rhizophoraceae (Jain et al. 2001; Parida et al. 2002; Lin and Kao 1996; Bar-Nun and Poljakoff-Mayber 1977). In plants, proline is synthesized from glutamate as well as from ornithine. Under conditions of osmotic stress, the glutamate pathway predominates over the ornithine pathway, and plants convert more glutamate to proline than transaminate ornithine to $\Delta^{1}$-pyrroline-5-carboxylate (P5C) (Ginzberg et al. 1998). Glutamate is first phosphorylated by the kinase activity of the bifunctionnal enzyme $\Delta^{1}$ pyrroline-5-carboxylate synthetase (P5CS) to produce $\gamma$-glutamyl-phosphate, which is subsequently reduced by the reductase activity of P5CS to glutamic- $\gamma$ semialdehyde. This intermediate spontaneously cyclizes to P5C which is then reduced by the pyrroline-5-carboxylate reductase to proline (Armengaud et al. 2004). Promoter studies and transgenic approaches have shown that P5CS is the major rate-limiting step for proline accumulation (Hare et al. 1999). Two P5CS genes have been shown to be present in Arabidopsis thaliana, Medicago sativa, Medicago truncatula and Lycopersicon esculentum (Ginzberg et al. 1998; Armengaud et al. 2004; Strizhov et al. 1997; Fujita et al. 1998). P5CS1 and P5CS2 are differentially regulated upon development and/or osmotic stress according to species, suggesting different metabolic functions of these P5CS isoforms. Armengaud et al. (2004) suggested specific MtP5CS1 as housekeeping product and MtP5CS2 as a stress specific isoform in M. truncatula (Armengaud et al. 2004). Similarly, a rapid increase was observed in the steady-state transcript level of both genes in roots of $M$. sativa in response to salinity, suggesting that the both genes are salt-inducible, although MsP5CS2 response for salinity was higher (Ginzberg et al. 1998).

The second important osmolyte used by plants to tolerance stresses is glycine betaine (GB), which is an N-trimethyl derivative of glycine frequently reported from Chenopodiaceae, Amaranthaceae, Poaceae, Avicenniaceae plant families (McCue and Hanson 1992; Ishitani et al. 1993; Hibino et al. 2001; Legaria et al. 1998). The GB contributes to salt tolerance by maintaining turgor pressure and protecting macromolecular structures and the biochemical reactions of the photosystem against salt stress (Papageorgiou and Murata 1995; Zhao et al. 1992). In addition, exogenous GB supplies also protect plants from stress (Demiral and Turkan 2006). In plants, GB is biosynthesized by a two-step oxidation of choline via an intermediate form of betaine aldehyde. Most of the GB biosynthetic enzymes are induced by environmental abiotic stresses. Betaine 
aldehyde dehydrogenase (BADH) catalyzes the last irreversible step and converts betaine aldehyde to GB, and BADH is crucial in the biosynthesis of GB (Asuku et al. 2009). Many BADH genes have been isolated from different plant species mostly in Chenopodiaceae, Amaranthaceae, Poaceae and Avicenniaceae, and reported to play an important role in the tolerance of plants not only to salinity but also to droughtness (Zhang et al. 2008).

To our best knowledge, BADH genes have not been isolated from Medicago sativa, and its osmolyte role not reported in Leguminosae, although some studies have reported that BADH-transgenic $M$. sativa enhanced the salt tolerance (Liu et al. 2011). This work reports the expression, cloning and sequencing of BADH gene through inducing salinity stresses in cotyledons and young roots of $M$. sativa, and studies the expression pattern of P5CS2 in this species.

\section{MATERIAL AND METHODS}

Plant materials: Medicago sativa L. (alfalfa, Fabaceae) is an important forage crop across the world, where salinity and water stresses limit crop productivity. Alfalfa is best adapted to medium textured soils with a $\mathrm{pH}$ between 6 and 8. It requires a minimum of 10 to 12 inches of precipitation annually, at least half of which should be received as rain (opposed to snow). Alfalfa originates from southwestern Asia. It was first cultivated in Iran, and now has a worldwide distribution as an agricultural crop (Hulten, 1968; Royer and Dikinson 1999). Different cultivars of $M$. sativa are cultivated as the most important leguminous forage crops in northwest of Iran including Syah-Roud, Gara-Yonjeh, Hasht-Roud, Khor-Khor and Bash-Kand, of which Gara-Yonjeh has the highest tolerant to salinity. It is, therefore, widely cultivated in most parts of Northwest of Iran as the main forage crop (Monirifar, 2008).

Plants cultivation and treatments: The seeds Medicago sativa cv. GaraYonjeh were provided by Azarbaijan Agricultural Research Center and Natural Resources, Tabriz, Iran. The seeds were surface-sterilized using 5 percent (v/v) sodium-hypochlorite and germinated in Petri dishes $(20 \mathrm{~cm}$ diameter) containing two layers of filter paper. Five different salinity concentrations included in the study were as follow: 0 (control), 50, 100, 150 and $200 \mathrm{mM} \mathrm{NaCl}$, and for each treatment 30 seeds were used. Four replicates were designed for each concentration. Germination was carried out in growth chambers with a $16 \mathrm{~h}$ photoperiod (Sylvania cool white fluorescent lamps, $200 \mathrm{mmol} / \mathrm{m}^{2} / \mathrm{s}$ and $400-700$ $\mathrm{nm})$. Two-day-old seedlings under treatment were used for physiological, biochemical and molecular analyzes.

We obtained the threshold salinity concentration in the seedlings of $M$. sativa cv. Gara-Yonjeh under stresses on the basis of significant decrease in fresh weight (FW). This concentration was found to be $150 \mathrm{mM}$.

Physiological and biochemical analyzes: The concentration of $\mathrm{Na}^{+}, \mathrm{K}^{+}$and $\mathrm{Ca}^{2+}$ were separately measured in cotyledon and young roots of the Two-day-old seedlings under treatment using flame photometer followed by washing in 
disabled water for $5 \mathrm{~min}$ digesting them in hydrochloric acid $(1: 15 \mathrm{w} / \mathrm{v})$. Free proline content was determined in the both cotyledon and young roots following the method of Bates et al. (1973).

RT-PCR analyzes: In plants under study the mRNA levels of $\Delta^{1}$-pyrroline5-carboxylate synthetase (hereafter is called MsP5CS2) and Betaine aldehyde dehydrogenase (hereafter is called MsBD1) were determined in cotyledon and young roots of Two-day-old seedling under 0 and $150 \mathrm{mM}$ salt concentrations using semi-quantative RT-PCR analysis. Total RNA was extracted from $200 \mathrm{mg}$ of cotyledon and young roots of seedling from both control and treatment samples under $150 \mathrm{mM} \mathrm{NaCl}$ using RNX-Plus (CinnaGen, Iran) solution according to the manufacturer's instructions. In order to produce single-stranded cDNA, after treating with DNase, total RNA samples were reverse-transcribed using RevertAid ${ }^{\mathrm{TM}}$ First Strand cDNA Synthesis Kit (Fermentas, Burlington, Canada). In synthesizing cDNA, $4 \mu \mathrm{g}$ total RNA, $1 \mu \mathrm{L}$ M-MuLV reverse transcriptase, $1 \mu \mathrm{L}$ RNase inhibitor, $1 \mu \mathrm{L}$ Oligo(dT) 18 primer and $2 \mu \mathrm{L}$ dNTP Mix at $37^{\circ} \mathrm{C}$ for $1 \mathrm{~h}$, then the reaction was terminated at $70{ }^{\circ} \mathrm{C}$ for $10 \mathrm{~min}$. The total volume of the reverse-transcription reaction system was $20 \mu \mathrm{L}$.

In order to investigate the occurrence of coding region of P5CS2 and MsBD1 in cDNA, the cDNA was separately PCR-amplified using primers of $5^{\prime}$ CTCTGATTCAACTGATTGC-3' and 5'-GCAGCCTGCAATGCAATGG-3' for P5CS2 gene, and primers 5'-ATGGATATTCCGATCCC-3' and 5'TCACAGTTTTGCAGGAGG-3' for MsBD1 gene. The primers sequences for P5CS2 were previously reported by Ginzberg et al. (1998) in Medicago sativa, which amplify $506 \mathrm{bp}$ fragments.

MsBD1 primers were designed in this study using sequences of BADHs of the following species presented in NCBI by OLIGO6 (Rychlik 2000): Medicago truncatula (GenBank accession no. XM-003608880.1), Pisum sativum (GenBank accession no. AJ315853.2), Glycin max (GenBank accession no. XM003550706.1), Glycin max (GenBank accession no. NM-001251498.1), Ricinus communis (GenBank accession no. XM-002511417.1), Cucumis melo (GenBank accession no. JN091961.1), Brassica napus (GenBank accession no. AY351634.1) (Ye et al. 2005; Brauner et al. 2003; Arai et al. 2008). These primers produced a singular PCR band of $1518 \mathrm{bp}$ from cDNA of $M$. sativa $\mathrm{cv}$. Gara-Yonjeh, with amplification conditions of an initial denaturation at $94{ }^{\circ} \mathrm{C}$ for $5 \mathrm{~min}$, followed by 30 cycles of $94^{\circ} \mathrm{C}$ for $60 \mathrm{~s}, 55^{\circ} \mathrm{C}$ for $60 \mathrm{~s}, 72^{\circ} \mathrm{C}$ for $120 \mathrm{~s}$, then a final extension at $72{ }^{\circ} \mathrm{C}$ for $10 \mathrm{~min}$. A 286bp fragment of alfalfa species glyceraldehyde-3-phosphate dehydrogenase (GPDH) gene, used as an internal control, was amplified with the specific primers: 5' GTGGTGCCAAGAAGGTTGTTAT-3' and 5' CTGGGaAtGATGTTGAAGGAAG-3' (Bao et al. 2009). Amplification conditions for the GPDH fragment were an initial denaturation at $94{ }^{\circ} \mathrm{C}$ for $2 \mathrm{~min}$, followed by 25 cycles of $94{ }^{\circ} \mathrm{C}$ for $30 \mathrm{~s}, 54{ }^{\circ} \mathrm{C}$ for $30 \mathrm{~s}, 72{ }^{\circ} \mathrm{C}$ for $45 \mathrm{~s}$, then a final extension at $72{ }^{\circ} \mathrm{C}$ for $8 \mathrm{~min}$. The PCR products were electrophoresed on a 1.5 percent agarose gel containing ethidium bromide. The mRNA quantity of 
MsBD1 and P5CS2 genes were estimated as proportional of GPDH gene concentration and these ratios were considered as indication of the relative quantities of MsBD1 and P5CS2 mRNA levels. The band intensities of PCR products of cDNA were analyzed using UVIDoc software (UVP, USA).

Cloning: To confirm the presence of BADH, the amplified DNAs were purified using Wizard SV Gel and PCR Clean-Up system (Promega, Madison,WI) and cloned into pTZ57R/T vector with a TA cloning system (Fermentas, Burlington, Canada). Positive clones were selected for sequencing by MWG-Biotech AG (Ebersberg, Germany). An amino acid sequence was proposed for BADH gene using Generunner software.

The CLUSTALW online program (http://www.ebi.ac.uk/Tools/clustalw) was used to construct a phylogenetic tree based on the deduced amino acid sequences of MsBD1, and other BADHs from taxonomically 10 distant plant families of Angiosperms including Poaceae, Salicaceae, Corylaceae, Chenopodiaceae, Amaranthaceae, Vitiaceae, Brassicaceae, Euphorbiaceae, Fabaceae, Cucurbitaceae and Asteraceae, in order to investigate the evolutionary relationships among BADHs.

Statistical analysis: Data are presented as the mean \pm SD (standard deviation) for each treatment $(\mathrm{n}=4)$. Significance of differences among treatments were analyzed by one-way ANOVA using Tukey (HSD) test at the $P<0.05$ probability level.

\section{RESULTS}

In the present study, treating $M$. sativa cv. Gara-Yonjeh seedlings with different $\mathrm{NaCl}$ concentration of $0,50,100,150$ and $200 \mathrm{mM}$ showed that the plant fresh weight increased 10 percent at $50 \mathrm{mM} \mathrm{NaCl}$ concentration and then gradually decreased by increasing salt concentrations. The lowest level of fresh weight was obtained at $200 \mathrm{mM}$ concentration by 46 percent decrease (Figure 1).

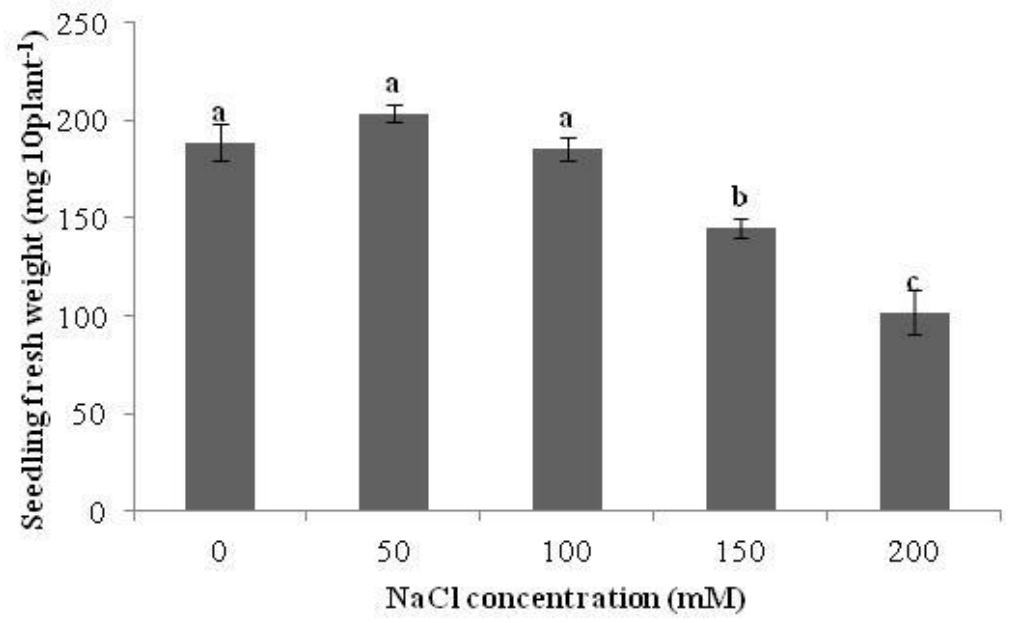

Figure 1: Effect of $\mathrm{NaCl}$ concentration on seedlings fresh weight (FW) in Medicago sativa cv. Gara-Yonjeh. Vertical bars represent standard deviation of 
the mean $(n=4)$. Bars indicated by different letters differ significantly $(P<$ 0.05), while those of the same letters are not different

The $\mathrm{Na}^{+}$accumulation significantly increased by increasing $\mathrm{NaCl}$ concentration from 50 to $200 \mathrm{mM}$ both in cotyledon and young roots. $\mathrm{Na}^{+}$ accumulation increased dramatically from 95 percent to 269 percent in young roots, and from 218 percent to 382 percent in cotyledon (Figures 2 and 3).

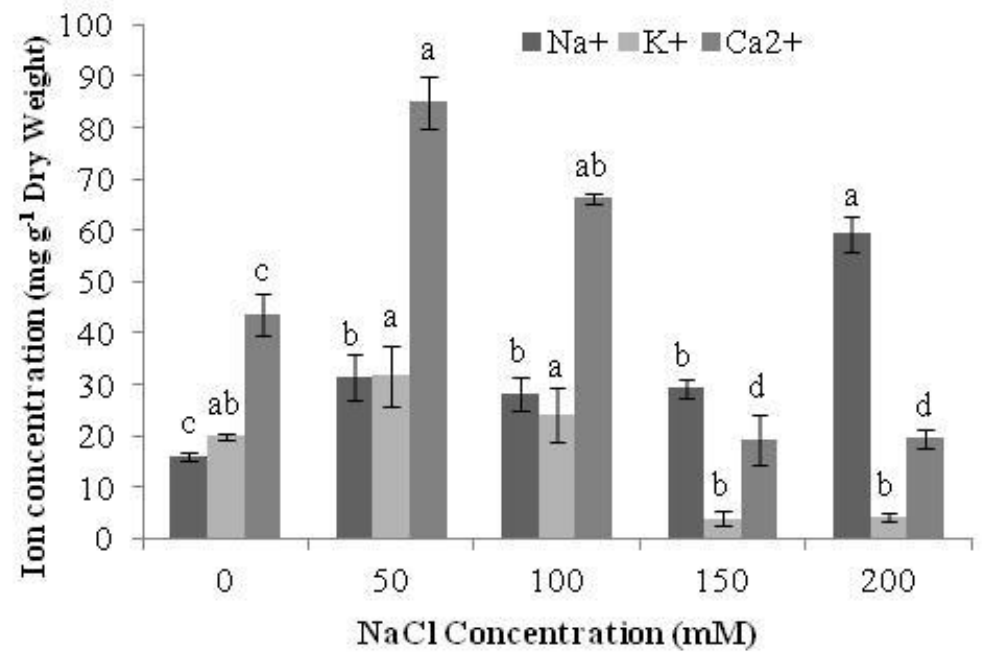

Figure 2: Effect of $\mathrm{NaCl}$ concentration on the $\mathrm{Na}+\mathrm{K}+$ and $\mathrm{Ca} 2+$ content of cotyledons in Medicago sativa cv. Gara-Yonjeh. The variation of each cation was compared among different $\mathrm{NaCl}$ concentrations. Vertical bars represent standard deviation of the mean $(n=4)$. Bars indicated by different letters are significantly different $(\mathrm{P}<0.05)$, while those of the same letters are not different

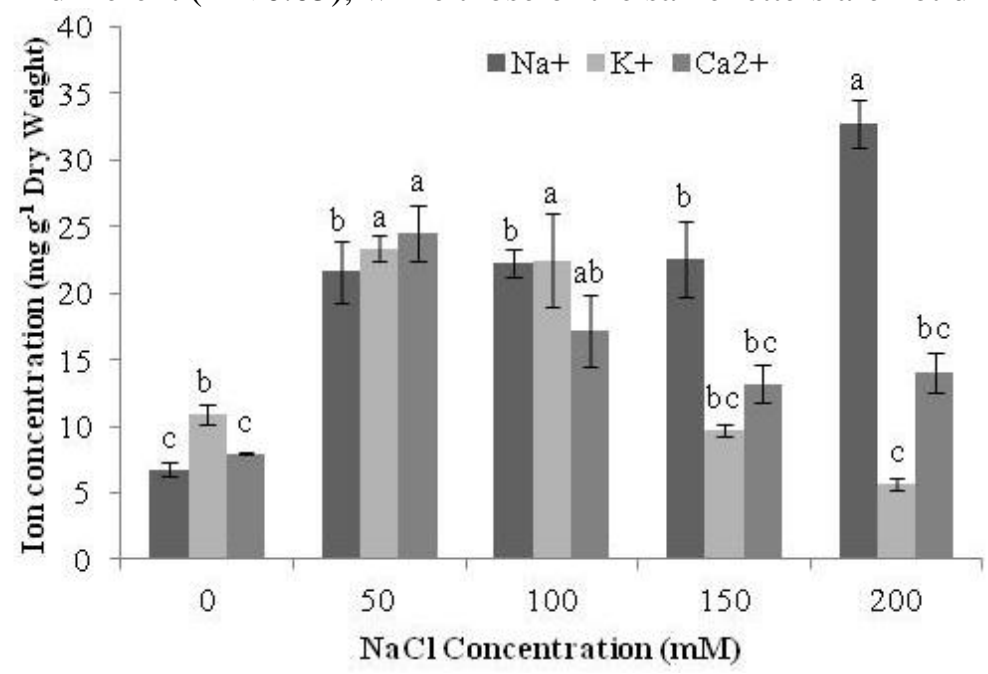

Figure 3: Effect of $\mathrm{NaCl}$ concentration on $\mathrm{Na}+\mathrm{K}+$ and $\mathrm{Ca} 2+$ contents in young roots of Medicago sativa cv. Gara-Yonjeh. The variation of each cation was compared among different $\mathrm{NaCl}$ concentrations. Vertical bars represent standard 
deviation of the mean $(n=4)$. Bars indicated by different letters are dramatically different $(\mathrm{P}<0.05)$, while those of the same letters are not different

The accumulation of $\mathrm{K}^{+}$significantly increased at the $\mathrm{NaCl}$ concentration of 50 and $100 \mathrm{mM}$, but this accumulations dramatically decreased both in cotyledon and young roots by at 150 and 200mM (Figures 2 and 3), consequently the $\mathrm{Na}^{+} / \mathrm{K}^{+}$and $\mathrm{Na}^{+} / \mathrm{Ca}^{2+}$ ratios increased in both roots and shoots by increasing salt concentration.

Under salt stress the seedlings accumulated significantly higher levels of proline in both cotyledon and young roots so that by increasing salt concentration from 50 to $200 \mathrm{mM}$, proline concentration increased gradually from 158 percent to 729 percent in cotyledon, and from 201 percent to 489 percent in young roots (Figure 4).

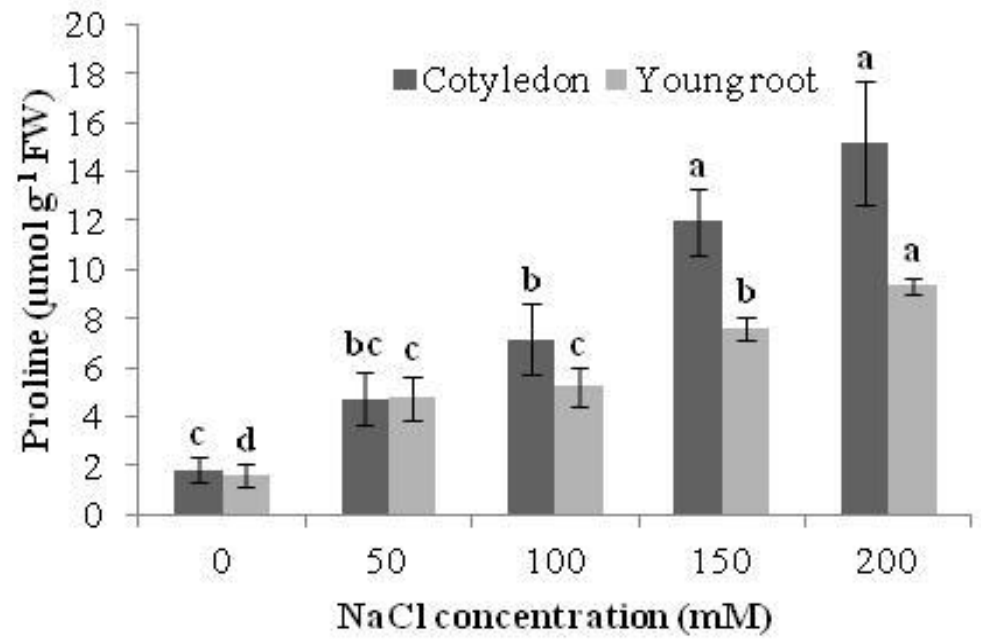

Figure 4: Effect of $\mathrm{NaCl}$ concentration on the proline accumulation in cotyledons and young roots of Medicag sativa cv. Gara-Yonjeh. Vertical bars represent standard deviation of the mean $(n=4)$. Bars indicated by different letters differ remarkably $(P<0.05)$, while those of the same letters are not different.

In both tissues the mRNA levels of MsP5CS2 and MsBD1 increased at $\mathrm{NaCl} 150 \mathrm{mM}$ compared to control. Based on gel intensity compared to the control, the mRNA levels of MsP5CS2 in the cotyledons and young roots dramatically increased by 49 percent and 45 percent, respectively, while these increases were 5 percent and 9 percent for the levels of MsBD1 mRNA (Figure 5). Comparison their expressions in cotyledon and young roots showed that MsP5CS2 transcripts expression was stronger in the former tissues, while MsBD1 transcripts were stronger in latter tissues.

A cDNA fragment of 1518 bp was isolated by the RT-PCR method and cloned into the pTZ57R/T vector with a TA cloning system (Fermentas, Burlington, Canada) (Figure 6). 

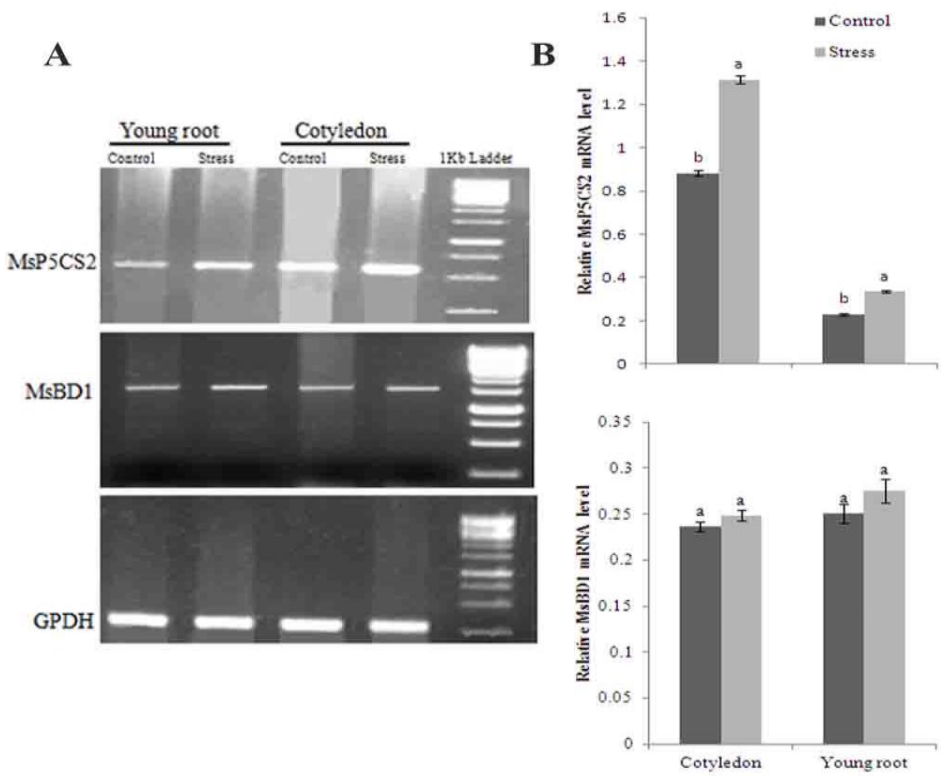

Figure 5: The mRNA expression of GPDH, MsP5CS2 and MsBD1 genes in Medicago sativa cv. Gara-Yonjeh under control and $150 \mathrm{mM} \mathrm{NaCl}$ stresses. (A) The gel photos for GPDH, MsP5CS2 and MsBD1 genes. A single band for each gene was detected in both cotyledons and roots. (B) Relative mRNA quantities of MsBD1 gene detected in gel lane were normalized using GPDH gene mRNA intensities. The means for four independent replications are plotted with standard deviations bars.

$\begin{array}{llll}1 & \text { ATGGATATTCCGATCCCGTCTCGACAGTTATTCATTAACGGTGACTGGAAATCTCCCATC } & 60 \\ 61 & \text { CTCAACAAACGTATTCCCGTCATCAACCCCTCTACTCAACAAACCATCGGGGATATCCCA } & 120 \\ 121 & \text { GCGGCTACCAAGGAAGATGTAGACGCCGCCGTTGCCGCTGCTAAGACTGCCCTCTCTCGT } & 180 \\ 181 & \text { AACAAAGGCGCTGATTGGGCTTCCGCTTCTGGCGCTGTTCGTGCTCGCTATCTACGCGCT } & 240 \\ 241 & \text { ATCGCTGCTAAGGTTACTGAGAAAAAATCAGAACTCGCCAAGCTTGAAGCTATTGATTCC } & 300 \\ 301 & \text { GGTAAACCACTCGATGAAGCCGCGTGGGACATGGATGATGTTGCTGGTTGTTTTGAGTTT } & 360 \\ 361 & \text { TACGCTGATCTTGCTGAAAAATTGGATGCAAAGCAAAAGGCTCCTGTTTCTCTTCCAATG } & 420 \\ 421 & \text { GATACATTTAGGAGTCATGTCCTTAGGGAGCCTATTGGTGTTGTTGGATTAAAAACTCCA } & 480 \\ 481 & \text { TGGAACTATCCTCTGTTGATGATCACGTGGAAGGTTGTTCCCTGTCTTGCTTCTGGTTGT } & 540 \\ 541 & \text { GTTGCGATATTGAAGCCATCTGAATTGGCATTTTTAACTTGCTTGGAGTTGGGCGAAATA } & 600 \\ 601 & \text { TGCAAAGAAGTGGACCTTCCTCCGGGCGTATTAAATATTCTCACTGGATTAGGCCTTGAA } & 660 \\ 661 & \text { GCCGGTGCTCCTTTGGCATCCCCATCCCTGATGTTGACAAGATTGCTTTTACTGGAAGCT } & 720 \\ 721 & \text { CTGCAACTGGGAGCAAAAATTATGACAGCTGCAGCTCAGCTGGTCAAGCCTGTTTTCACT } & 780 \\ 781 & \text { GGAGCTTGGTGGAAAAAGCCCATAATTGTTTTGAGGACGTTGACCTTGATAAGGCTGCG } & 840 \\ 841 & \text { GAATGGGCAATCTTCGGTGGTTCTGGACAAATGGTCAGATATGCAGTGCAACTTTCCCG } & 900 \\ 901 & \text { TCTTTATTGTACATGAAAGTAGAGCAACAGAATTTTTGATAGGATGGTGAAATGGATC } & 960 \\ 961 & \text { AAAAACATCAAAATTTCAGATCCCTTGGAAGAAGGTTGCAGGCTAGGACCTGTTGTTAGT } & 1020 \\ 1021 & \text { GAAGGACAGTACGAAAAAATATTGAAGTTTGTCTCGAACGCTAAGAGTGAGGGTGCGACA } & 1080 \\ 1081 & \text { ATTTTGACTGGTGGGTCTCGACCAGAGCATCTAAAGAAAGGATTCTTTGTGAACCAACC } & 1140 \\ 1141 & \text { ATCATAACTGATGTGACTACTTCCATGCAAATTTGGAAAGAAGAAGTATTTGGACCTGTT } & 1200 \\ 1201 & \text { CTGTGTGTAAAAACGTTTAGCACCGAGGAAGAAGCTATTGATCTAGCAAATGACACTATC } & 1260 \\ 1261 & \text { TATGGCTTAGGTGCTGCTGTAATATCAAATGATCTAGAAAGATGTGAGCGAGTAATTAAG } & 1320 \\ 1321 & \text { GCATTTAAGGCCGGAATAGTATGGGTCAATAGCTCTCAGGAAAAAGACAATCAAGCGCCT } & 1380 \\ 1381 & \text { AGGGGAGGCAGTAAACGTAGTGGTTTTGGCCGTGAACTAGGAGAATGGGGATTGGACAAT } & 1440 \\ 1441 & \text { TACTTGAGTGTGAAGCAAGTGACTCAGTACATCTCTGATGAACCATGGGGCTGGTACCAA } & 1500 \\ 1501 & \text { CCTCCTGCAAAACTGTGA } & \text { 1518 } & \end{array}$

Figure 6: The nucleic acid sequences of the MsBD1 gene obtained from Medicago sativa cv. Gara-Yonjeh under salinity stress of $150 \mathrm{mM} \mathrm{NaCl}$ concentration 
Nucleotide BLAST search showed that the isolated cDNA fragment from M. sativa cv. Gara-Yonjeh (recorded in GenBank as accession no.JX312735) shared high sequence homology with many known BADH genes from several plant species such as 96 percent with Medicago truncatula (GenBank accession no. XM-003608880.1), 90 percent with Pisum sativum (GenBank accession no. AJ315853.2), 89 percent with Glycin max (GenBank accession no. XM003550706.1), 86 percent with Glycin max (GenBank accession no. NM001251498.1), 78 percent with Ricinus communis (GenBank accession no. XM002511417.1), 78 percent with Cucumis melo (GenBank accession no. JN091961.1) and 76 percent with Brassica napus (GenBank accession no. AY351634.1) (Ye et al. 2005; Brauner et al. 2003; Arai et al. 2008).

An amino acid sequence we proposed for MsBD1 gene sequence obtained in this study using of Generunner software comprises of 505 amino acids (Figure 7).

$\begin{array}{lll}1 & \text { MDIPIPSRQLFINGDWKSPILNKRI PVINPSTQQTIGDIPAAT KEDVDAAVAAARTALSR } & 60 \\ 61 & \text { NKGADWASASGAVRARYLRAIAAKVTEKKSELAKLEAIDSGKPLDEAAWDMDDVAGCFEF } & 120 \\ 121 & \text { YADLAEKLDAKQKAPVSLPMDTFRSHVLREPIGVVGLTPWNYLLMITWKVVPCLASGC } & 180 \\ 181 & \text { VAILKPSELAFLTCLELGEICKEVDLPPGVLNILTGLGLEAGAPLASPSLMLTRLLLLEA } & 240 \\ 241 & \text { LQLGAKIMTAAAQLVKPVFTGAWWKPIIVFEDVDLDKAAEWAIFGCFWTNGQICSATFP } & 300 \\ 301 & \text { SLLYMKVEQQNFLNRMVKWIKNIKISDPLEEGCRLGPVVSEGQYEKILKFVSNAKSEGAT } & 360 \\ 361 & \text { ILTGGSRPEHLKKGFFVETTITDVTTSMQIWKEEVFGPVLCVKTFSTEEEAIDLANDTI } & 420 \\ 421 & \text { YGLGAAVISNDLERCERVIKAFKAGIVWVNSSQEKDNQAPRGGSKRSGFGRELGEWGLDN } & 480 \\ 481 & \text { YLSVKQVTQYISDEPWGWYQPPAKL 505 } & \end{array}$

Figure 7: The proposed amino acid sequence for MsBD1 gene obtained M. sativa cv. Gara-Yonjeh under salinity stress of $150 \mathrm{mM} \mathrm{NaCl}$ concentration

Comparison our proposed MsBD1 amino acid sequence to those of BADH protein reported from several well-known plant species presented in NCBI database using BlastP program analysis showed high homology. This homology was 89 percent with Medicago truncatula (GenBank accession no. XP003608928.1), 81 percent with Glycin max (GenBank accession no. ADNO3184.1), 75 percent with Ricinus communis (GenBank accession no. XP002511463.1), 75 percent with Corylus heterophylla (GenBank accession no.ADW80331.1), 75 percent with Populus euphratica (GenBank accession no.AFA53116.1), 74 percent with Jatropha curcus (GenBank accession no. AB069575.1), 74 percent with Arabidopsis thaliana (GenBank accession no.NP565094.1), 74 percent with Cucumis melo (GenBank accession no. AEK81574.1), 74 percent with Populus trichocarpa (GenBank accession no.XP_002322147.1), 73 percent with Panax ginseng (GenBank accession no.AAQ76705.1), 73 percent with Vitis vinifera (GenBank accession no.XP_002283690.1), 72 percent with Helianthus annuus (GenBank accession no.ACU65243.1), 72 percent with Amaranthus hypochondriacus (GenBank accession no.AAB70010.1), 71 percent with Brassica napus (GenBank accession no. AAQ55493.1), 68 percent with Beta vulgaris (GenBank accession no.BAE07176.1), 68 percent with Spinacia oleraceae (GenBank accession no.ACM67311.1), 68 percent with Atriplex prostrata (GenBank accession no.AAM08913.1), 68 percent with Zoysia tenuifolia (GenBank accession 
no.BAD34956.1) and 67 percent with Zea mays (GenBank accession no.NP_001157804) (Zhang et al. 2008; Ye et al. 2005; Arai et al. 2008; Gardiner et al. 2004; Juwattanasomran et al. 2011; Oishi and Ebina 2005; Yu et al. 2005; Tabuchi et al. 2006; Legaria et al. 1998; Tuskan et al. 2006; Theologis et al. 2000).

The CLUSTALW analysis of MsBD1 amino acid sequences proposed in this study and those of BADHs suggested for other plant species showed that MsBD1 has the closest relationship to BADHs of Brassicaceae and Cucurbitaceae (Figure 8).

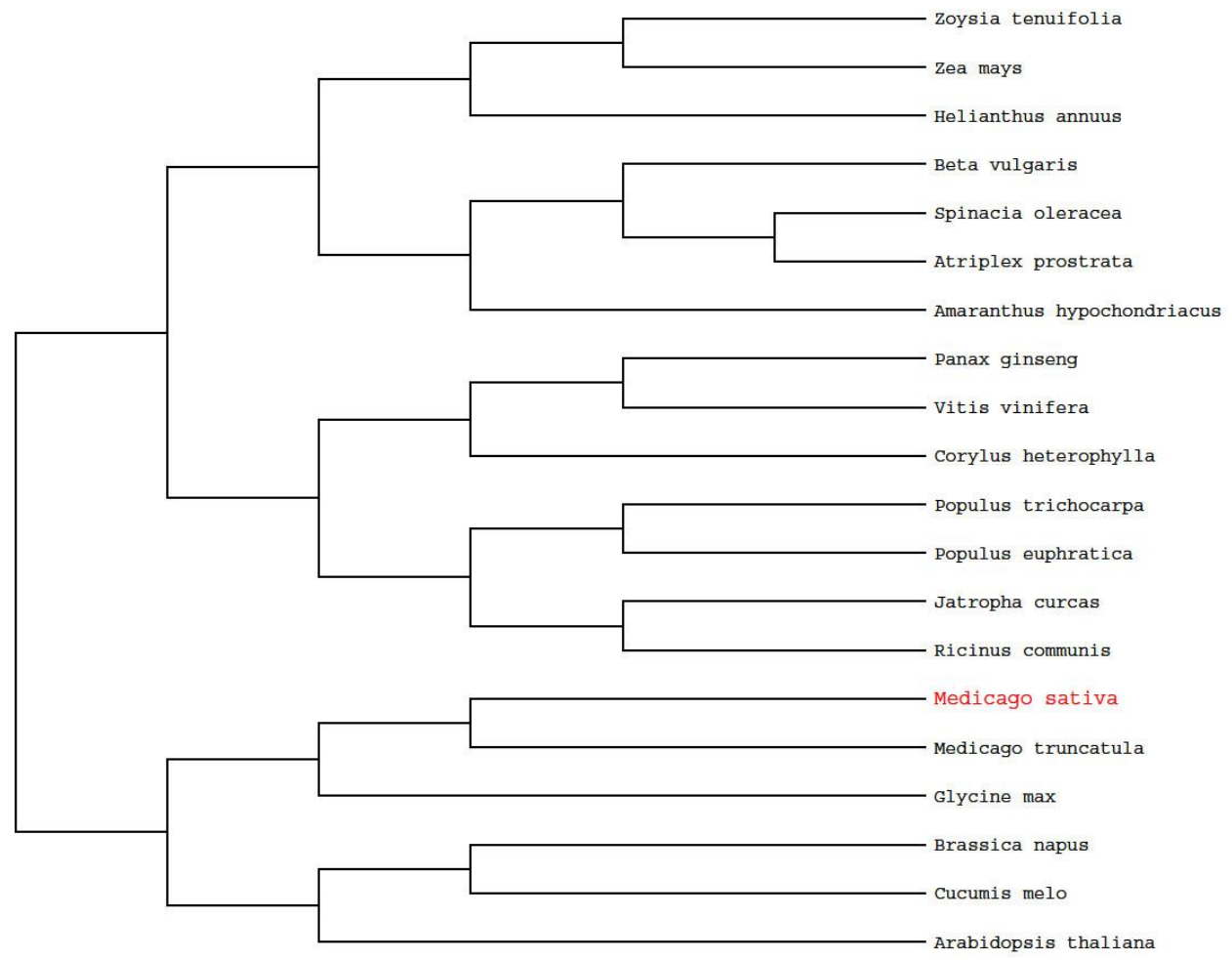

Figure 8: The dendrogram showing similarity between amino acid sequences of MsBD1 reported in this study from Medicago sativa cv. Gara-Yonjeh and BADH genes of several plant species (see text for plant species)

\section{DISCUSSION}

In the present study Medicago sativa cv. Gara-Yonjeh growth was significantly inhibited by salt stress at high concentration $(150 \mathrm{mM})$ while it increased at low concentration $(50 \mathrm{mM})$. Therefore, $150 \mathrm{mM}$ of $\mathrm{NaCl}$ was considered as threshold salinity stress in Gara-Yonjeh cultivar. In a very recent study on the impact of salinity on Medicago sativa cv. Elci. Altinok and Yurtseven (2015) have shown that irrigation water salinities of $0.25,1.5$ and 3 $\mathrm{dS} / \mathrm{m}$ of $\mathrm{NaCl}$ and $\mathrm{CaCl} 2$ did not significantly affect on the total green and dry forage yields. A similar investigation on three different cultivars of the cultivated 
Gossypium Hirsitum L. (cotton, Malvaceae) showed that the water salinity threshold ranged from $\mathrm{Ct}=3.72$ to $\mathrm{Ct}=4.45$ and that the salinity of irrigation water up to the $4.45 \mathrm{dS} / \mathrm{m}$ did not significantly affect on loss on seed-cotton yield (Uzen and Unlu 2015). A salinity concentration $50 \mathrm{mM}$ of $\mathrm{NaCl}$ in the leguminosae Alhagi pseudalhagi was found to increase the plant growth, while $200 \mathrm{mM}$ was deteced as the threshold stress concentration, at which the plant dry weight decreased by 42.7 percent compared with control plants (Kurban et al. 1999).

Our results showed that under salt stress the M. sativa cv. Gara-Yonjeh accumulated different solutes of inorganic types e.g. $\mathrm{Na}^{+}, \mathrm{K}^{+}$and $\mathrm{Ca}^{2+}$ and organic ones e.g. proline to high concentration in both cotyledon and young roots. To maintain an osmotic gradient for the uptake of water from sediments, many plants accumulate inorganic ions to a concentration equal to or greater than that of the surrounding root solution (Bradley and Morris 1991). In the current study the $\mathrm{Na}^{+}$accumulation was gradually increased by increasing $\mathrm{NaCl}$ concentration in both cotyledon and young roots of M. sativa cv. Gara-Yonjeh. The accumulation of $\mathrm{K}^{+}$and $\mathrm{Ca}^{2+}$ was promoted by a moderate concentration of $\mathrm{NaCl}$ while at high $\mathrm{NaCl}$ concentration, their accumulation decreased. Consequently, the $\mathrm{Na}^{+} / \mathrm{K}^{+}$and $\mathrm{Na}^{+} / \mathrm{Ca}^{2+}$ ratios increased at high salinity in both tissues. These results suggest that salt tolerance in M. sativa cv. Gara-Yonjeh is related to a high cation accumulation capacity. On the other hand, shifts in these cations ratio under salinity stresses cause dramatic decrease in growth of $M$. sativa cv. Gara-Yonjeh, and similar results have been reported from many other plant species (Moghaieb et al. 2004).

In addition to accumulations of cations as a response to salinity stress, $M$. sativa cv. Gara-Yonjeh accelerated the expression of P5CS2 genes to high level, and also accumulated significantly higher levels of proline in both cotyledon and young roots though much higher in cotyledon than in young roots. Higher levels of P5CS2 genes expression observed under salt stresses in our work was also reported from other Medicago species under the same stress (Ginzberg et al. 1998; Armengaud et al. 2004), where MtP5CS2 transcripts were strongly accumulated in shoots, but poorly in all other organs (Armengaud et al. 2004). Osmotic adjustment is a mechanism used for maintaining turgor and reducing the deleterious effects of water stress on vegetative and reproductive organs. It is well known that osmotic adjustment involves the net accumulation of solutes in a cell in response to salinity. Consequently, the osmotic potential decrease, which in turn uptakes water into the cell and enables turgor to be maintained.

In this paper, we reported a gene sequence coding BADH isolated from cDNA of M. sativa cv. Gara-Yonjeh and named as MsBD1. The high homology (e.g. 98 percent) between our BADH sequence and those sequences reported from other plant species (Ye et al. 2005; Brauner et al. 2003; Arai et al. 2008) confirms that the sequence isolated from M. sativa cv. Gara-Yonjeh in the current study is the most likely coding sequence for BADH. Moreover, the higher levels of match ( $>68$ percent) between the BADH amino acid sequence proposed in the 
current study with those of this gene reported from several other plant species provide further support the authenticity of the MsBD1 cDNA sequence (Zhang et al. 2008; Ye et al. 2005; Arai et al. 2008; Gardiner et al. 2004; Juwattanasomran et al. 2011; Oishi and Ebina 2005; Yu et al. 2005; Tabuchi et al. 2006; Legaria et al. 1998; Tuskan et al. 2006; Theologis et al. 2000). Phylogenetic tree showed that MsBD1 has its closest relationships with BADHs from other plant species of the Brassicaceae and Cucurbitaceae families and similar results have been reported from Pisum sativum (Brauner et al. 2003) (Fig. 8). As one of the most important enzymes for GB synthesis in plants, BADHs have been intensively studied and demonstrated to be associated with stress tolerance in many plant species from a wide taxonomic range especially Chenopodiaceae, Amaranthaceae, Poaceae, Avicenniaceae and others (McCue and Hanson 1992; Wood et al. 1996). In the present study the level of BADH mRNA slightly increased under salt stress, and this increase was relatively higher in the roots than in the shoots. This pattern was also observed in the control group. On the other hand, there are several different forms of betaines in different genotypes of $M$. sativa, $M$. truncatula, $M$. littoralis, $M$. rugosa and $M$. polymorpha including Proline betaine, pipecolate betaine, trigonelline, hydroxyproline betaine and GB (Trinchant et al. 2004). In M. sativa Proline betaine is released by alfalfa seeds during germination, and works as an inducer of nodulation (nod) genes in the alfalfa-symbiont of Rhizobium (Sinorhizobium meliloti) (Phillips et al. 1992; Phillips et al. 1995). Our results suggest that BADH play no important role on salinity tolerance in M. sativa cv. Gara-Yonjeh and probably it plays a crucial role on regulation of symbiotic relationship.

\section{CONCLUSION}

The results of this study suggest that the cations accumulation and their subsequent sequestration in vacuoles, and the synthesis of compatible solutes (e.g. proline), and expression of BADH genes to some extent are the main strategy that have evolved in M. sativa cv. Gara-Yonjeh to maintain growth under high salinity through maintaining osmotic adjustment. Although several families particularly Chenopodiaceae, Amaranthaceae, and Poaceae accumulate GB in large quantity in response to salinity stress, our study show that the plant studied does not accumulate GB as response to salinity.

\section{ACKNOWLEDGEMENT}

We would like to thank the Research Directory of the University of Tabriz for funding this project.

\section{REFERENCES}

Altinok, S., Yurtseven, E., Avci, S., Öztürk, H.S. \& Selenay, M.F. (2015): The effects of different irrigation water salinities and leaching ratios on green and dry forage yields of alfalfa (Medicago sativa 1.). Agriculture and Forestry, 61(1): 85-90. 
Arai, Y., Hayashi, M. \& Nishimura, M. (2008): Proteomic analysis of highly purified peroxisomes from etiolated soybean cotyledons. Plant Cell Physiol., 49(4): 526539.

Armengaud, P., Thieryc, L., Buhota, N., Grenier-de Marchb, G. \& Savoure, A. (2004): Transcriptional regulation of proline biosynthesis in Medicago truncatula reveals developmental and environmental specific features. Physiol. Plant, 120: 442-450.

Asuku Hattori, T., hiro Mitsuya, S., Fujiwara, T., Jagendorf, A.T. \& Takabe, T. (2009): Tissue specificity of glycinebetaine synthesis in barley. Plant Sci., 176: 112-118.

Bao, A.K., Wang, S.M., Wu, G.Q., Xi, J.J., Zhang, J.L. \& Wang, C.M. (2009): Overexpression of the Arabidopsis H+-PPase enhanced resistance to salt and drought stress in transgenic alfalfa (Medicago sativa L.). Plant Sci., 176: 232-240.

Bar-Nun, N. \& Poljakoff-Mayber, A. (1977): salinity stress and the content of proline in roots of Pisum sativum and Tamarix tetragyna. Ann Bot., 41: 173-179.

Bates, L.S., Waldren, R.P. \& Teare, I.D. (1973): Rapid determination of free proline for water stress studies. Plant Soil., 39: 205-207.

Boscari, A., Mandon, K., Dupont, L., Poggi, M.C. \& Rudulier, D.L. (2002): BetS Is a Major Glycine Betaine/Proline Betaine Transporter Required for Early Osmotic Adjustment in Sinorhizobium meliloti. J Bacteriol., 184(10): 2654-2663.

Bradley, P.H. \& Morris, J.T. (1991): Relative importance of ion exclusion, secrtion and accumulation in Sparina alterniflora Loisel. J Exp Bot., 42: 1525-1532.

Brauner, F., Sebela, M., Snegaroff, J., Pec, P. \& Meunier, J.C. (2003): Pea seedling aminoaldehyde dehydrogenase: primary structure and active site residues. Plant Physiol Biochem., 41(1): 1-10.

Demiral, T. \& Turkan, I. (2006): Exogenous glycinebetaine affects growth and proline accumulation and retards senescence in two rice cultivars under $\mathrm{NaCl}$ stress. Environ Exp Bot., 56: 72-79.

Fujita, T., Maggio, A., Garcia-Rios, M., Bressan, R.A. \& Csonka, L.N. (1998): Comparative analysis of the regulation of expression and structures of two evolutionarily divergent genes for Delta1-pyrroline-5-carboxylate synthetase from tomato. Plant Physiol., 118: 661-674.

Gardiner, J., Schroeder, S., Polacco, M.L., Sanchez-Villeda, H., Fang, Z., Morgante, M., Landewe, T., Fengler, K., Useche, F., Hanafey, M., Tingey, S., Chou, H., Wing, R., Soderlund, C. \& Coe, E.H.Jr. (2004): Anchoring 9,371 maize expressed sequence tagged unigenes to the bacterial artificial chromosome contig map by two-dimensional overgo hybridization. Plant Physiol., 134(4): 1317-1326.

Ginzberg, I., Stein, H., Kapulnik, Y., Szabados, L., Strizhov, N., Schell, J., Koncz, C. \& Zilberstein, A. (1998): Isolation and characterization of two different cDNAs of 11-pyrroline-5-carboxylate synthase in alfalfa, transcriptionally induced upon salt stress. Plant Mol Biol., 38: 755-764.

Hare, P.D., Cress, W.A. \& Van Staden, J. (1999): Proline synthesis and degradation: a model system for elucidating stress-related signal transduction. J Exp Bot., 50: 413-434.

Hibino, T., Meng, Y.L., Kawamitsu, Y., Uehara, N., Matsuda, N., Tanaka, Y., Ishikawa, H., Baba, S., Takabe, T., Wada, K., Ishii, T. \& Takabe, T. (2001): Molecular cloning and functional characterization of two kinds of betaine-aldehyde dehydrogenase in betaine-accumulating mangrove Avicennia marina (Forsk.) Vierh. Plant Mol Biol., 45(3): 353-363.

Hultén, E. (1968): Flora of Alaska and Neighboring Territories. Stanford: Stanford University Press. 
Ishitani, M., Arakawa, K., Mizuno, K., Kishitani, S. \& Takabe, T. (1993): Betaine aldehyde dehydrogenase in the Gramineae: levels in leaves of both betaineaccumulating and nonaccumulating cereal plants. Plant Cell Physiol., 34(3): 493 495.

Jain, M., Mathur, G., Koul, S. \& Sarin, N.B. (2001): Ameliorative effects of proline on salt stress-inducing lipid peroxidation in cell lines of groundnut (Arachis hypogaea L.). PLant Cell Rep., 20: 463-468.

Juwattanasomran, R., Somta, P., Chankaew, S., Shimizu, T., Wongpornchai, S., Kaga, A. \& Srinives, P. (2011): A SNP in GmBADH2 gene associates with fragrance in vegetable soybean variety 'Kaori' and SNAP marker development for the fragrance. Theor Appl Genet., 122(3): 533-541.

Kurban, H., Saneoka, H., Nehira, K., Adilla, R., Premachandra, G.S. \& Fujita, K. (1999): Effect of salinity on growth, photosynthesis and miniral compostion in leguminous plant Alhagi pseudoalhagi (Bieb). Soil Sci Plant Nutr., 45: 851-862.

Legaria, J., Rajsbaum, R., Munoz-Clares, R.A., Villegas-Sepulveda, N., Simpson, J. \& Iturriaga, G. (1998): Molecular characterization of two genes encoding betaine aldehyde dehydrogenase from amaranth. Expression in leaves under short-term exposure to osmotic stress or abscisic acid. Gene., 218(1-2): 69-76.

Lin, C.C. \& Kao, C.H. (1996): Proline accumulation is associated with inhibition of rice seeding root growth caused by $\mathrm{NaCl}$. Plant Sci., 114: 121-128.

Liu, Z.H., Zhang, H.M., Li, G.L., Guo, X.L., Chen, S.Y., Liu, G.B. \& Zhang, Y.M. (2011): Enhancement of salt tolerance in alfalfa transformed with the gene encoding for betaine aldehyde dehydrogenase. Euphytica., 178: 363-372.

McCue, K.F. \& Hanson, A.D. (1992): Salt-inducible betaine aldehyde dehydrogenase from sugar beet: cDNA cloning and expression. Plant Mol Biol., 18: 1-11.

Moghaieb, R.E.A., Saneoka, H. \& Fujita, K. (2004): Effect of salinity on osmotic adjustment, glycinebetaine accumulation and the betaine aldehyde dehydrogenase gene expression in two halophytic plants, Salicornia europaea and Suaeda maritima. Plant Sci., 166: 1345-1349.

Monirifar, H. (2008). Tolerance of Five Azarbaijan Alfalfa Ecotypes to Salinity. International Meeting on Soil Fertility Land Management and Agroclimatology; 709-713.

Oishi, H. \& Ebina, M. (2005): Isolation of cDNA and enzymatic properties of betaine aldehyde dehydrogenase from Zoysia tenuifolia. J Plant Physiol., 162(10): 10771086.

Papageorgiou, G.C. \& Murata, N. (1995): The unusually strong stabilizing effects of glycinebetaine on the structure and function in the oxygen-evolving photosystem II complex. Photosynthetica., 44: 243-252.

Parida, A., Das, A.B. \& Das, P. (2002): NaCl stress causes changes in photosynthetic pigments, proteins and other metabolic components in the leaves of a true mangrove, Bruguiera parviflora, in hydroponic cultures. J Plant Biol., 45: 28-36.

Phillips, D.A., Joseph, C.M. \& Maxwell, C.A. (1992): Trigonelline and stachydrine released from alfalfa seeds activate NodD2 protein in Rhizobium meliloti. Plant Physiol., 99: 1526-1531.

Phillips, D.A., Wery, J., Joseph, C.M., Jones, A.D. \& Teuber, L.R. (1995): Release of flavonoids and betaines from seeds of seven Medicago species. Crop Sci., 35: 805-808.

Royer, F. \& Dickinson, R. (1999): Weeds of the Northern United States and Canada, Edmonton: University of Alberta Press. 
Rychlik, W. (2000): OLIGO: primer analysis software. West Cascade, CO, USA.

Silva-Ortega, C.O., Ochoa-Alfaro, A.E., Reyes-Agu“ero, J.A., Aguado-Santacruz, G.A. \& Jime'nez-Bremont, J.F. (2008): Salt stress increases the expression of p5cs gene and induces proline accumulation in cactus pear. Plant Physiol Biochem., 46: 8292.

Strizhov, N., Abraham, E., Okresz, L., Blickling, S., Zilberstein, A., Schell, J., Koncz, C. \& Szabados, L. (1997): Differential expression of two P5CS genes controlling proline accumulation during salt-stress requires $\mathrm{ABA}$ and is regulated by $\mathrm{ABA} 1$, ABI1 and AXR2 in Arabidopsis. Plant J., 12: 557-569.

Tabuchi, T., Okada, T., Takashima, Y., Azuma, T., Nanmori, T. \& Yasuda, T. (2006): Transcriptional response of glycinebetaine-related genes to salt stress and light in leaf beet. Plant Biotechnol., 23: 317-320.

Theologis, A., Ecker, J.R., Palm, C.J., Federspiel, N.A., Kaul, S., White, O., et al. (2000): Sequence and analysis of chromosome 1 of the plant Arabidopsis thaliana. Nature., 408(6814): 816-820.

Trinchant, J.C., Boscari, A., Spennato, G., Van de Sype, G. \& Le Rudulier, D. (2004): Proline betaine accumulation and metabolism in alfalfa plants under sodium chloride stress. exploring its compartmentalization in nodules1. Plant Physiol., 135: $1583-1594$.

Tuskan, G.A., Difazio, S., Jansson, S., Bohlmann, J., Grigoriev, I., Hellsten, U., Putnam, N., Ralph, S., Rombauts, S., Salamov, A., Schein, J., Sterck, L., Aerts, A., Bhalerao, R.R., et al. (2006). The genome of black cottonwood, Populus trichocarpa (Torr. \& Gray). Science., 313(5793): 1596-1604.

Uzen, N. \& Unlu, M. (2015): Evaluation on effects of different salinity levels in irrigation water for certain cotton varieties under southeastern Anatolia region conditions. Agricultue and Forestry, 61(2): 109-118.

Wood, A.J., Saneeoka, H., Rhodes, D., Joly, R.J. \& Goldsbrough, P.B. (1996): Betaine aldehyde dehydrogenase in sorghum. Plant Physiol., 110(4): 1301-1308.

Ye, C., Wu, S., Yang, Q., Ma, C., Yang, G. \& Wang, B. (2005): Cloning, sequencing and salt induced expression of PEAMT and BADH in oilseed rape (Brassica napus). DNA Seq., 16(5): 364-371.

Yu, J., Wang, J., Lin, W., Li, S., Li, H., Zhou, J., Ni, P., Dong, W., Hu, S., Zeng, C., Zhang, J., Zhang, Y., Li, R., Xu, Z., Li, S., et al. (2005): The Genomes of Oryza sativa: a history of duplications. PLoS Biol., 3(2): 38.

Zhang, F.L., Niu, B., Wang, Y.C., Chen, F., Wang, S.H., Xu, Y., Jiang, L.D., Gao, S., Wu, J., Tang, L. \& Jia, Y.J. (2008): A novel betaine aldehyde dehydrogenase gene from Jatropha curcas, encoding an enzyme implicated in adaptation to environmental stress. Plant Sci., 174: 510-518.

Zhao, Y.D., Aspinall, D. \& Paleg, L.G. (1992): Protection of membrane integrity in Medicago sativa L. by glycinebetaine against the effects of freezing. Plant Physiol., 140: 541-543 